Research Article

\title{
Multisource Ground Motion Attenuation Relationship Model for the Vertical Component of the Wenchuan Earthquake on May 12, 2008
}

\author{
Ping Liu $\mathbb{D}^{1},{ }^{1}$ Tongjie Ren, ${ }^{1}$ Hai Wang, ${ }^{2}$ Chunfeng Li, ${ }^{3}$ Baoqiang Wang $\mathbb{D},{ }^{4}$ and Zhengwei Xu ${ }^{1}$ \\ ${ }^{1}$ School of Architecture and Civil Engineering, Xi'an University of Science and Technology, Xi'an 710054, China \\ ${ }^{2}$ Shanxi Transportation Survey \& Design Institute Co., Ltd., Taiyuan 030032, China \\ ${ }^{3}$ Guizhou Transportation Planning Survey \& Design Academe Co., Ltd., Guiyang 550081, China \\ ${ }^{4}$ School of Architecture and Urban Planning, Huazhong University of Science and Technology, Wuhan 430074, China
}

Correspondence should be addressed to Baoqiang Wang; 2015210248@hust.edu.cn

Received 8 January 2021; Accepted 12 June 2021; Published 25 June 2021

Academic Editor: Yixian Wang

Copyright $(\odot 2021$ Ping Liu et al. This is an open access article distributed under the Creative Commons Attribution License, which permits unrestricted use, distribution, and reproduction in any medium, provided the original work is properly cited.

\begin{abstract}
In order to extend the multisource model to vertical ground motion, we fit the vertical ground motion attenuation relationship of the Wenchuan earthquake. Different from traditional attenuation relationship forms, we propose a simplified ground motion attenuation function including site effect via a flag related to $V_{S 30}$. The regression results show that it has site effect on the vertical ground motion of the Wenchuan earthquake and gradually weakens with the increase in periods. According to residuals analysis, the hanging-wall effect on vertical ground motion is strong for the Wenchuan earthquake, especially in short periods. The result analysis indicates that the shape of the vertical response spectrum based on regression is different from that of the horizontal component and complies with the recommended design vertical response spectrum of FEMA P-1050. V/H (vertical-to-horizontal ratios), as a main way to estimate vertical ground motion, cannot be simply fixed as $2 / 3$. Therefore, site location, site condition, and frequency spectrum have to be considered comprehensively. The regression accuracy of the vertical ground motion of the multisource model is slightly higher than that of the point-source model and lower than that of the finite fault source model. It is expected that this model will serve as an alternative for source-to-site distance when multiple asperities are to be modeled in the absence of the detail fault model to get a general scenario of the future ground motions.
\end{abstract}

\section{Introduction}

An $M_{W} 7.9$ earthquake occurred on May 12, 2008, in Wenchuan, Sichuan province, China. Except for Heilongjiang, Jilin, and Xinjiang provinces, it was felt all over the country, especially in Sichuan, Shaanxi, and Gansu provinces. The earthquake caused major losses to the economy and people's lives; at the same time, the China Digital Strong Motion Observation Network (CDMON) equipped in March 2008 obtained a large amount of highquality ground motion [1]. These data have greatly enriched the database on strong ground motion in China and have also provided a valuable opportunity for studying ground motion attenuation relationship of large earthquakes.
Ground motion attenuation relationship, also known as ground motion prediction equation, is an empirical correlation between ground motion parameter and earthquake characteristics (source, source-to-site distance, site condition, etc.) [2]. The relationship is widely used in probabilistic seismic hazard analysis (PSHA), earthquake early warning engineering, ShakeMap, etc. [3]. For small and medium earthquakes or far-field earthquakes, the epicentral distance or hypocentral distance based on the point-source model is chosen as the source-to-site distance, and highly popular in China because of its usefulness and convenience in PSHA. However, the point-source model is far from suitable for large earthquakes, especially ones with long fault rupture. And fault distance based on the finite fault source model is 
recommended to reduce the scatter in the estimates of the strong ground motion of large earthquakes in near field [4]. However, it is hard to predict the related source parameters describing the fault rupture plane: the fault dip, rupture length, down-dip rupture width, depth-to-top of rupture, etc. Therefore, we proposed the multisource model (also called the multicircle model in $[5,6]$ ) based on the conclusion of synthesizing ground motion of the mainshock of the Tangshan earthquake $\left(M_{S} 7.6\right)$ on July 28,1976 [7] (see Figure 1). The basic assumptions of the multisource model are as follows:

(1) Fault rupture caused by the mainshock is divided into a set of subfaults

(2) A subfault has one center, called subepicenter (for the subfault where the epicenter is located, the epicenter is also called as the subepicenter)

(3) The subfault closest to the site has the greatest effect on ground motion, with others neglected

The subepicentral distance from the site to the closest subepicenter is defined to represent the source-to-site distance parameter. Due to the short fault rupture for a small magnitude earthquake, it is considered as one subfault only; the longer fault could be divided into multiple subfaults with increase in magnitudes. Abrahamson and Silva's model (AS08) believes when the moment magnitude is less than 6.0, the difference among various distance parameters could be ignored [8]. Mark and Bonilla's equation calculates the length of fault rupture for an $M_{W} 6.0$ earthquake as about $16 \mathrm{~km}$ [9]. Therefore, when the length of fault rupture is smaller than or equal to $16 \mathrm{~km}$, there is only one subfault; when it is larger than $16 \mathrm{~km}$, multiple subfaults would be recommended. And the equation calculating the subepicentral distance is as follows:

(1) The projection of the site on the strike of seismogenic fault is located between neighboring subsource epicenters, and the remaining number of $s$ divided by 16 is smaller than $8 \mathrm{~km}$ (see Figure 2(a)), with the subepicentral distance expressed as

$$
R_{M}=\sqrt{\operatorname{rem}(s, 16)^{2}+[R * \sin (D)]^{2}} .
$$

(2) The projection of the site on the strike of seismogenic fault is located between neighboring subsource epicenters, and the remaining number of $s$ divided by 16 was larger than or equal to $8 \mathrm{~km}$ (see Figure 2(b)), with the subepicentral distance expressed as

$$
R_{M}=\sqrt{[16-\operatorname{rem}(s, 16)]^{2}+[R * \sin (D)]^{2}} .
$$

(3) Others (see Figure 2(c)):

$$
R_{M}=\sqrt{[R * \cos (D)-d]^{2}+[R * \sin (D)]^{2}},
$$

where $R_{M}$ is the subepicentral distance in $\mathrm{km}$; $s$ is the distance from projection of the site on the strike of fault to the epicenter in $\mathrm{km}$ (when the projection

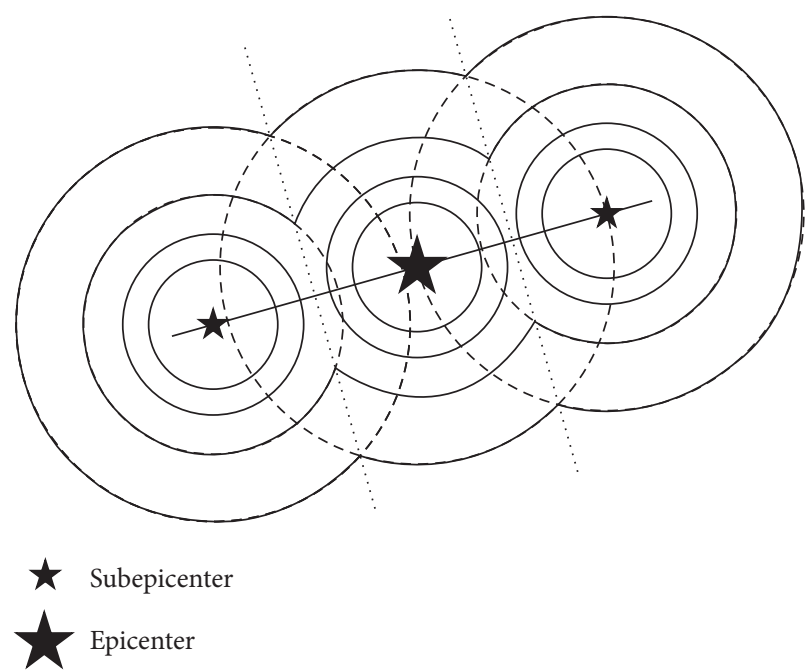

FIGURE 1: The principle of multisource model.

point was outside the fault, it was the distance from the epicenter to the end of the fault); $R$ is the epicentral distance in $\mathrm{km}$; $D$ is the azimuth angle (acute angle) between fault plane and ray path to site in degrees; $d$ is the distance from epicenter to the outermost subepicenter in $\mathrm{km}$; and rem is the remainder function.

The multisource model was used to fit the attenuation relationship for horizontal PGA (peak ground accelerations) in the Wenchuan earthquake [5] and horizontal ground motions of the NGA ("Next Generation of Ground-Motion Attenuation Models" project) database [6]. The result showed that the regression accuracy of the multisource model was higher than the point-source model and lower than the finite fault source model.

Research on earthquake damage from large earthquakes shows that the impact of vertical seismic action on structures cannot be ignored, especially on some functional buildings (e.g., long-span bridges, nuclear power plants, and dams) [10]. The horizontal ground motion attenuation relationship has attracted more attention than the vertical component. A brief review about studies on the characterization of vertical motions in the past three decades has summarized that vertical response spectra are most sensitive to spectral period and source-to-site distance and that $\mathrm{V} / \mathrm{H}$ response spectral ratios are generally higher on soil than on rock and at shorter periods than at longer periods [11]. Liu et al. [12], regressing vertical ground motions attenuation relationship of the Wenchuan earthquake based on the finite fault source model, found the same characters of the previous works. In recent years, the studies of vertical ground motions are still mainly based on the finite fault source model $[13,14]$ or the point-source model [15], and few people have tried other models. The purpose of this study is to extend the multisource model to vertical ground motion from the Wenchuan earthquake, focusing on attenuation characteristics, site effect, hanging-wall effect, and fitting accuracies comparison with other models. 


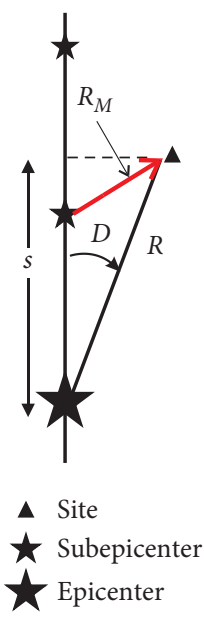

(a)

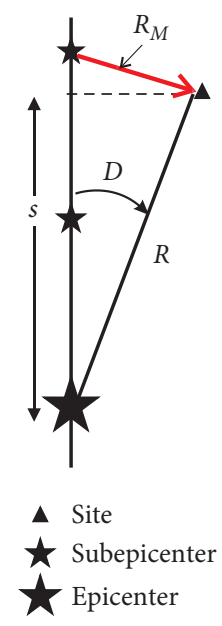

(b)

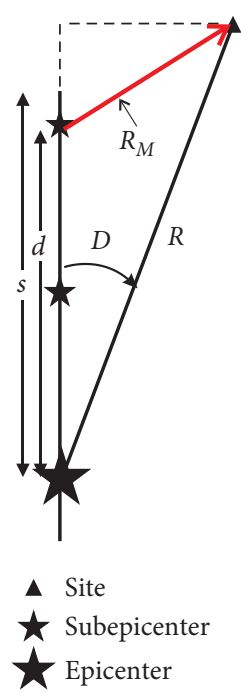

(c)

Figure 2: The principle of getting subepicentral distance. (a) The projection of site on strike between neighboring subsource epicenters, and the remaining number of (s) divided by 16 is smaller than $8 \mathrm{~km}$. (b) The projection of site on strike between neighboring subsource epicenters, and the remaining number of (s) divided by 16 is larger than or equal to $8 \mathrm{~km}$. (c) Others.

\section{Data on Strong Motion}

420 strong-motion seismometers were triggered over mainland China during the mainshock; most of them were processed and included in the NGA-West 2 database flatfile (https://peer.berkeley.edu/thrust-areas/data-sciences/

databases, last accessed on January 5, 2018). The detail of NGA-West2 strong-motion data processing was introduced by Ancheta et al. [16]. 91 free-field accelerograms recordings within a subepicentral distance of $300 \mathrm{~km}$ are selected to fit our model.

\section{Attenuation of Ground Motion}

We developed a simplified ground motion attenuation function:

$$
\ln Y=a_{0}+a_{1} * \ln \left(R_{M}+a_{2}\right)+a_{3} * R_{M}+a_{4} * F_{S},
$$

where $Y$ are the ground motion parameters such as PGA and PSA (pseudospectral acceleration) in $g$ and PGV (peak ground velocity) in $\mathrm{cm} / \mathrm{s} ; R_{M}$ is the subepicentral distance in $\mathrm{km} ; F_{S}$ is a flag for site effect; and $a_{0}, a_{1}, a_{2}, a_{3}$, and $a_{4}$ are regression coefficients based on the nonlinear least-squares method.

In equation (4), the first term $a_{0}$ represents the impact of the magnitude on ground motion; the second and third terms represent the geometric attenuation and inelastic attenuation of ground motion with distance, respectively; the last term represents the site effect. The first three terms are general forms for an attenuation relationship function. Site effect is also called amplification effect of site conditions on ground motion, which is expressed by a function of $V_{S 30}$ (the equivalent shear-wave velocity in the top $30 \mathrm{~m}$ ). $V_{S 30}$ of all recording stations in the Wenchuan earthquake range between $200 \mathrm{~m} / \mathrm{s}$ and $700 \mathrm{~m} / \mathrm{s}$, which belong to Class $\mathrm{C}$ and $\mathrm{D}$ sites [17]. The flag for site effect is as follows:

$$
F_{S}=\ln \left(V_{S 30} / V_{\mathrm{REF}}\right) \text {, }
$$

where $V_{S 30}$ is in $\mathrm{m} / \mathrm{s}$ and $V_{\mathrm{REF}}(360 \mathrm{~m} / \mathrm{s}$, the Class C-D site boundary here, eases to find the difference in the vertical ground motions of the two classes of sites) is the reference value of equivalent shear-wave velocity for site effect.

Hanging-wall effect is a geometric effect related to spatial relation between site and fault, and a significant characteristic of near-site ground motion of oblique fault. An example plot in Figure 3 illustrates the hanging-wall and foot-wall sites as used in this paper; the ground motion of site 2 on hangingwall is larger than that of site 1 on foot-wall, and even equal to source-to-site distance of them. Hanging-wall effect is discussed in this article by residual analysis.

\section{Result Analysis}

The regression coefficients, together with the standard deviation $\sigma_{\ln Y}$ of regression, are listed in Table 1 .

4.1. Site Effect. The corresponding median ground motion curves $\left(V_{S 30}=300 \mathrm{~m} / \mathrm{s}\right.$ for Class D site, while $V_{S 30}=500 \mathrm{~m} / \mathrm{s}$ for Class $C$ site) are compared with scatters of the data in Figure 4. Ground motion of Class D site (circle symbol) is significantly larger than that of Class $\mathrm{C}$ site (square symbol) for a short period (PGA); however, there is no obvious difference between the two class sites for a long period $(T=1.00 \mathrm{~s})$. The median ground motion has the same feature with changing periods. As shown in Table 1, site effect regression coefficient $a_{4}$ increases with the increase in periods and remains negative when the period is within $3.0 \mathrm{~s}$. The above analysis shows that, in short periods, the smaller the $V_{S 30}$ (the softer site) is, the greater the vertical ground 


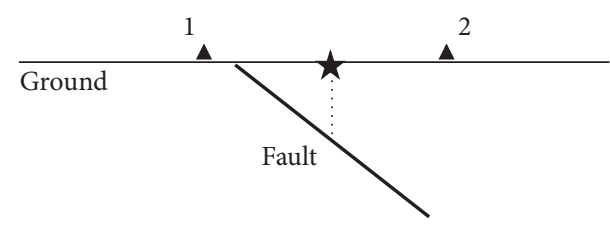

$\begin{array}{ll}\star & \text { Site } \\ \star & \text { Subepicenter }\end{array}$

FIGURE 3: The vertical section for principle of hanging-wall effect.

TABLE 1: Regression coefficients for vertical ground motion of the Wenchuan earthquake.

\begin{tabular}{|c|c|c|c|c|c|c|c|}
\hline Period & $a_{0}$ & $a_{1}$ & $a_{2}$ & $a_{3}$ & $a_{4}$ & $\sigma_{\ln Y}$ & $\mathrm{~N} / \mathrm{H}$ \\
\hline PGV & & & 14 & & & & \\
\hline & & & 14 & & & & \\
\hline & & & 14 & & & & \\
\hline & & & & & & & \\
\hline & & & 14 & & & & \\
\hline & & & 14 & & & & \\
\hline & & & 14 & & & & \\
\hline & & & 1 & & & & \\
\hline & & & & & & & \\
\hline & & & 1 & & & & \\
\hline & & & 14 & & & & \\
\hline & & & 14 & & & & \\
\hline & & & & & & & \\
\hline & & & 14 & & & & \\
\hline & & & 14 & & & & \\
\hline & & & & & & & \\
\hline & & & 1 & & & & \\
\hline & & & 14 & & & & \\
\hline & & & 14 & & & & \\
\hline & & & & & & & \\
\hline & & & 14 & & & & \\
\hline & & & 25 & & & & \\
\hline & & & 2 & & & & \\
\hline & & & & & & & \\
\hline $5.000 \mathrm{~s}$ & 0.192 & -0.939 & 14 & 0.00051 & 0.351 & 0.810 & 0.395 \\
\hline
\end{tabular}

Note. $0.010 \mathrm{~s}-3.000 \mathrm{~s}$ are $5 \%$ damping ratio PSA.

motion becomes; in long periods, the bigger the $V_{S 30}$ (the harder site) is, the greater the vertical ground motion becomes. So, the site effect gradually weakens with the increase in periods for vertical ground motion of the Wenchuan earthquake.

The intraevent residuals of vertical ground motion and binned mean versus $V_{S 30}$ are described in Figure 5. The average residuals for PGV, PGA, and PSA $(T=0.10 \mathrm{~s}$ and $1.00 \mathrm{~s})$ reach about $-2.94 \mathrm{e}-14,9.75 \mathrm{e}-16,1.03 \mathrm{e}-15$, and $2.21 \mathrm{e}-15$, respectively. There is no systematic trend for residuals with $V_{S 30}$, indicating that equation (5) gives rough estimate for site effect on vertical ground motion of the Wenchuan earthquake.

4.2. Hanging-Wall Effect. The near-site (within $50 \mathrm{~km}, R_{X}$ : horizontal distance to the top edge of the rupture measured perpendicular to strike) residuals are shown in Figure 6, with the data separated to hanging-wall $\left(R_{X}>0\right)$ and foot-wall $\left(R_{X}<0\right)$ sites. The residuals of the hanging-wall are obviously larger than those of the foot-wall except for a long period $(T=1.0 \mathrm{~s})$. The mean residuals of the hanging-wall are 0.1398 (PGV), 0.4636 (PGA), $0.5237(T=0.1 \mathrm{~s})$, and -0.1437 $(T=1.0 \mathrm{~s})$; those of foot-wall are $-0.0565(\mathrm{PGV}),-0.0820$ (PGA), $-0.0370(T=0.1 \mathrm{~s})$, and $0.0671(T=1.0 \mathrm{~s})$, indicating strong hanging-wall effect on vertical ground motion of the Wenchuan earthquake, especially in short periods.

4.3. Spectrum Shape. Figure 7 displays the vertical acceleration response spectrum of the Wenchuan earthquake with different distances when $V_{S 30}=300 \mathrm{~m} / \mathrm{s}$ and $V_{S 30}=500 \mathrm{~m} / \mathrm{s}$ based on regression. It is obvious that the intensity of spectrum when $V_{S 30}=300 \mathrm{~m} / \mathrm{s}$ is bigger than that when $V_{S 30}=500 \mathrm{~m} / \mathrm{s}$ in periods shorter than $2.0 \mathrm{~s}$, which is consistent with the above analysis of site effect. The vertical acceleration response spectrum increases to a peak point and then decreases with the increase in periods. The predominant period of vertical acceleration response spectrum is about $0.10 \mathrm{~s}$, which is shorter than that of the horizontal component.

The recommended design vertical response spectrum of FEMA P-1050 is as follows [18]:

$$
S_{v}= \begin{cases}0.375 S_{v \max }, & \text { for } T \leq 0.025 \mathrm{~s}, \\ S_{v \max } *(25 T-0.25), & \text { for } 0.025 \mathrm{~s}<T \leq 0.05 \mathrm{~s}, \\ S_{v \max }, & \text { for } 0.05 \mathrm{~s}<T \leq 0.15 \mathrm{~s}, \\ S_{v \max } *(0.15 / T)^{0.75}, & \text { for } T>0.15 \mathrm{~s}\end{cases}
$$

where $S_{v}$ is the design vertical response spectrum; $T$ is the vertical natural vibration period; and $S_{v \max }$ is the maximum (plateau) value of the design vertical acceleration response spectrum.

The shape of the design vertical response spectrum of FEMA P-1050 is different from that of GB 50011-2010 (2016 edition) (in Figure 8), and the latter is estimated by multiplying the design horizontal response spectrum by 0.65 [19]. Their main difference is range periods of plateau, which reaches $0.05 \mathrm{~s}$ to $0.15 \mathrm{~s}$ for FEMA P-1050 and $0.10 \mathrm{~s}$ to $T_{g}$ (characteristic period of horizontal ground motion) for $\mathrm{GB}$ 50011-2010 (2016 edition). As shown in Figures 7 and 8, the shape of vertical acceleration response spectrum based on regression complies with FEMA P-1050.

4.4. Vertical-to-Horizontal Ratios. In most cases of seismic design, vertical ground motion is estimated by multiplying horizontal ground motion by a fixed coefficient $(\mathrm{V} / \mathrm{H}) . \mathrm{V} / \mathrm{H}$ is $2 / 3$ proposed by Newmark and Hall [20]. Some scholars' research on $\mathrm{V} / \mathrm{H}$ indicates that $\mathrm{V} / \mathrm{H}$ is related to factors such as magnitude, distance, site type, period, and the like [21-26].

Generally, the relationship of $\mathrm{V} / \mathrm{H}$ is directly fitted by the least-squares method. However, this article adopted the following method [27]: 

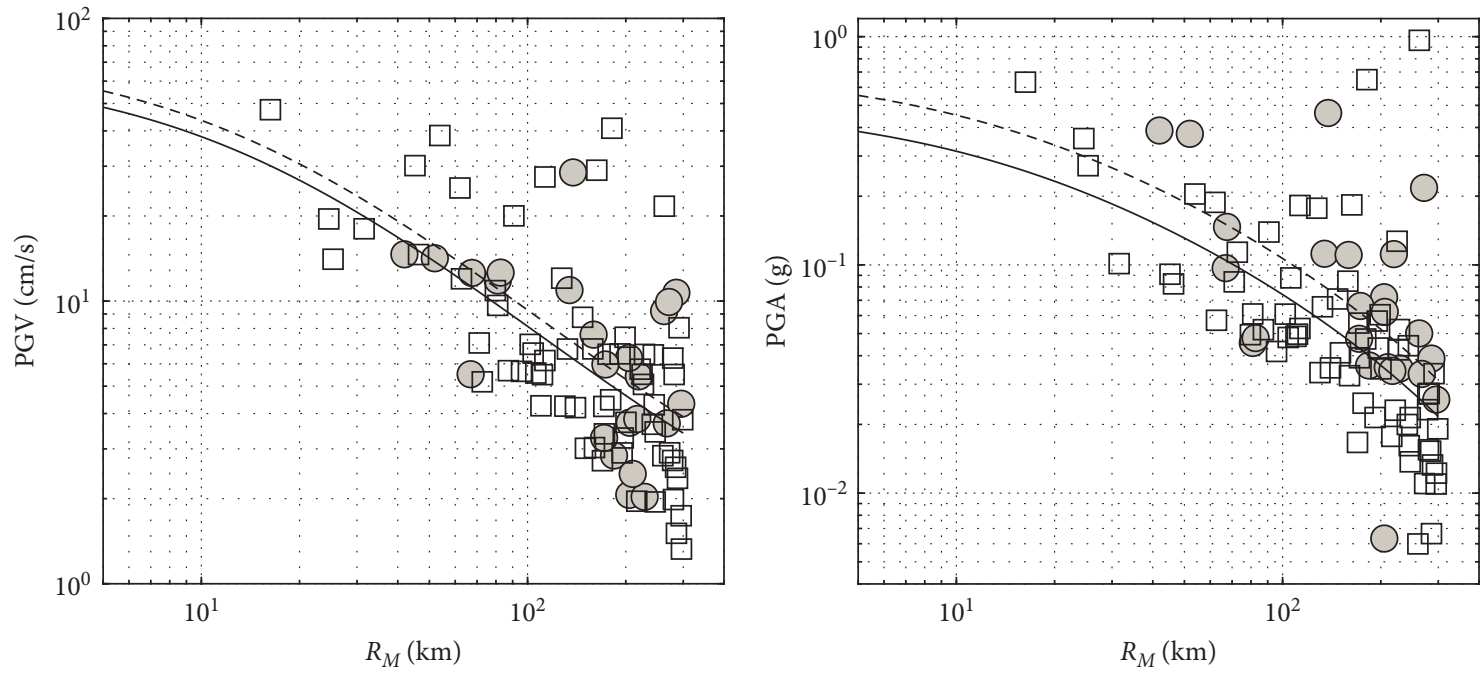

Wenchuan data $V_{S 30}<360 \mathrm{~m} / \mathrm{s}$

$\square$ Wenchuan data $V_{S 30}>360 \mathrm{~m} / \mathrm{s}$

- - Fitting curve $V_{S 30}=300 \mathrm{~m} / \mathrm{s}$

— Fitting curve $V_{S 30}=500 \mathrm{~m} / \mathrm{s}$

(a)

Wenchuan data $V_{S 30}<360 \mathrm{~m} / \mathrm{s}$

$\square$ Wenchuan data $V_{S 30}>360 \mathrm{~m} / \mathrm{s}$

- - Fitting curve $V_{S 30}=300 \mathrm{~m} / \mathrm{s}$

- Fitting curve $V_{S 30}=500 \mathrm{~m} / \mathrm{s}$

(b)

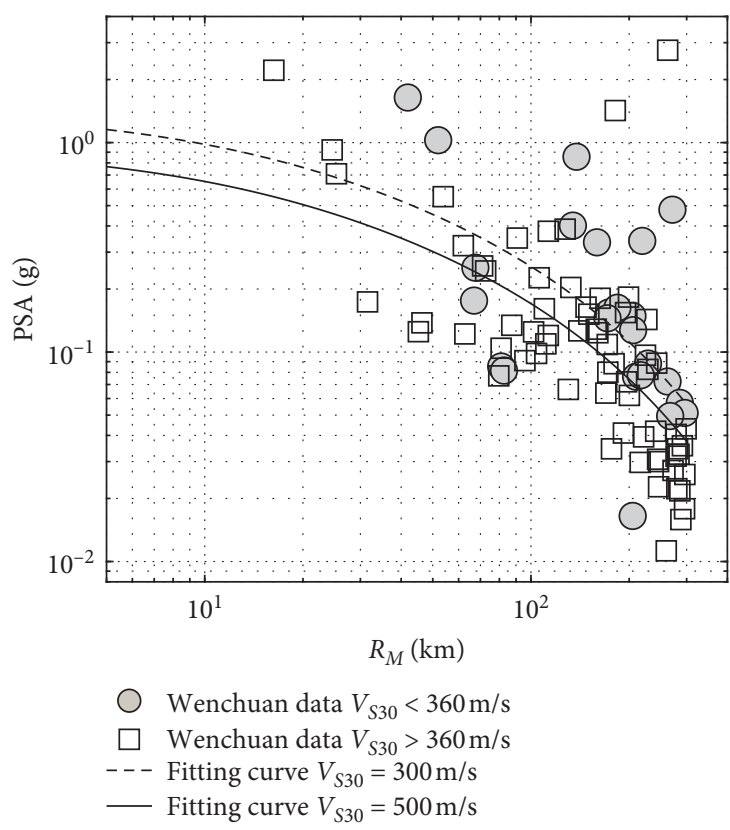

(c)

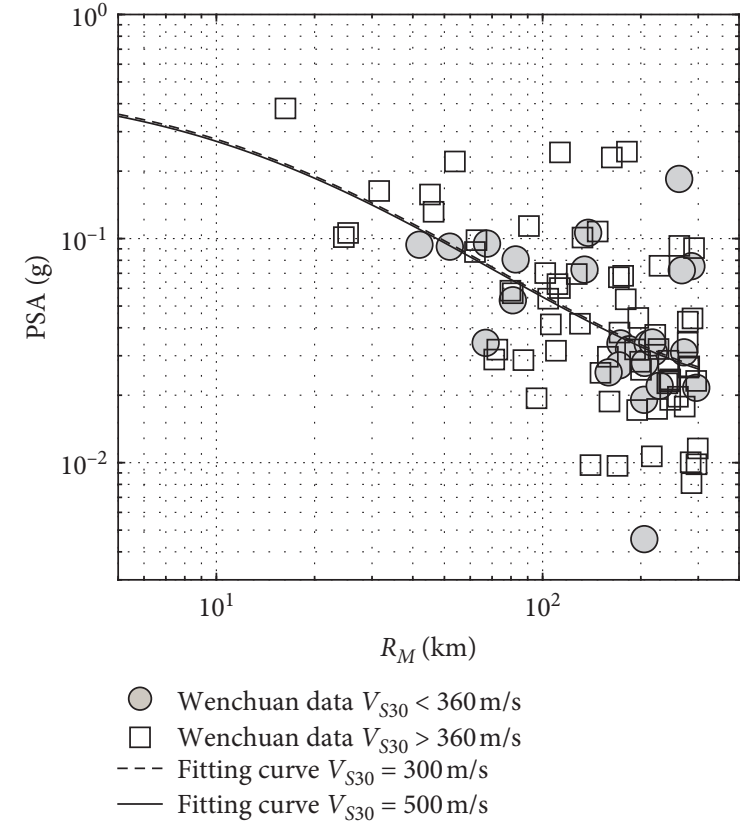

(d)

FIGURE 4: Multisource model of vertical ground motion attenuation of the Wenchuan earthquake. (a) PGV; (b) PGA; (c) 5\% PSA for 0.1 s; (d) $5 \%$ PSA for $1.0 \mathrm{~s}$.

$$
\ln (\mathrm{V} / \mathrm{H})=\ln Y_{\mathrm{v}}-\ln Y_{\mathrm{h}},
$$

where $\ln Y_{\mathrm{v}}$ and $\ln Y_{\mathrm{h}}$ are the fitted attenuation relationship using equation (4) for vertical and horizontal ground motion of the Wenchuan earthquake, respectively.

Standard deviation of equation (7) is given by

$$
\sigma_{\ln V / H}=\sqrt{\varphi_{\ln V / H}^{2}+\tau_{\ln V / H}^{2}},
$$

where

$$
\begin{aligned}
& \varphi_{\ln V / \mathrm{H}}=\sqrt{\varphi_{\ln Y_{\mathrm{v}}}^{2}+\varphi_{\ln Y_{\mathrm{h}}}^{2}+2 \rho_{\ln Y_{\mathrm{v}}, \ln Y_{\mathrm{h}}}^{\mathrm{W}} * \varphi_{Y_{\mathrm{v}}} * \varphi_{Y_{\mathrm{h}}}}, \\
& \tau_{\ln \mathrm{V} / \mathrm{H}}=\sqrt{\tau_{\ln Y_{\mathrm{v}}}^{2}+\tau_{\ln Y_{\mathrm{h}}}^{2}+2 \rho_{\ln Y_{\mathrm{v}}, \ln Y_{\mathrm{h}}}^{\mathrm{B}} * \tau_{Y_{\mathrm{v}}} * \tau_{Y_{\mathrm{h}}}},
\end{aligned}
$$

where $\sigma_{\ln V / \mathrm{H}}$ is the standard deviation of $\ln \mathrm{V} / \mathrm{H} ; \varphi_{\ln V / \mathrm{H}}$ and $\tau_{\operatorname{lnV} / \mathrm{H}}$ are the interevent standard deviation and intraevent standard deviation of $\ln \mathrm{V} / \mathrm{H}$, respectively; 


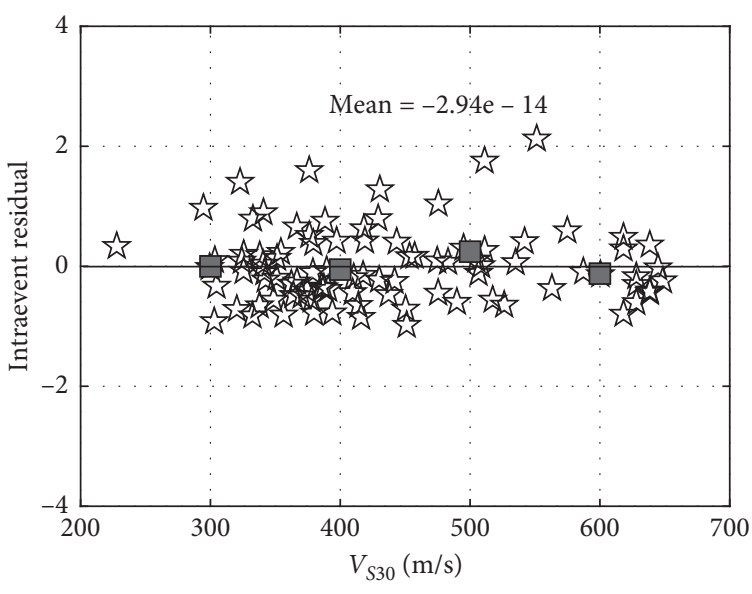

¿rs Residual

Binned mean

(a)

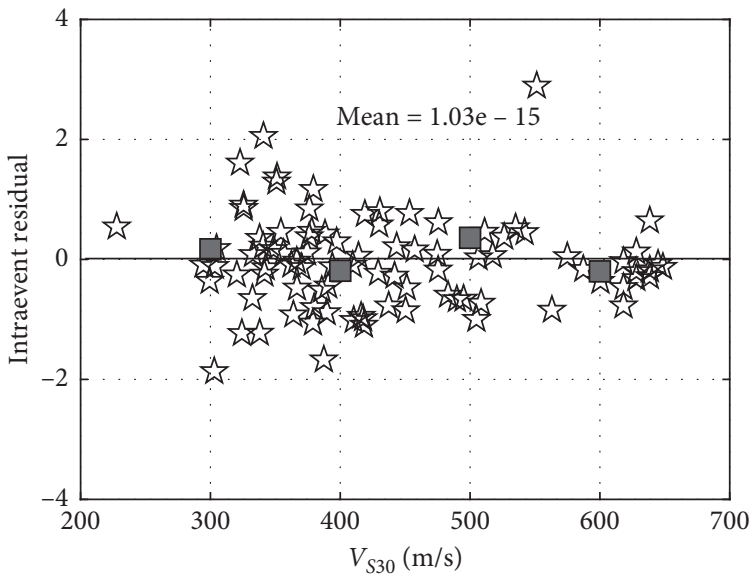

¿rs Residual

Binned mean

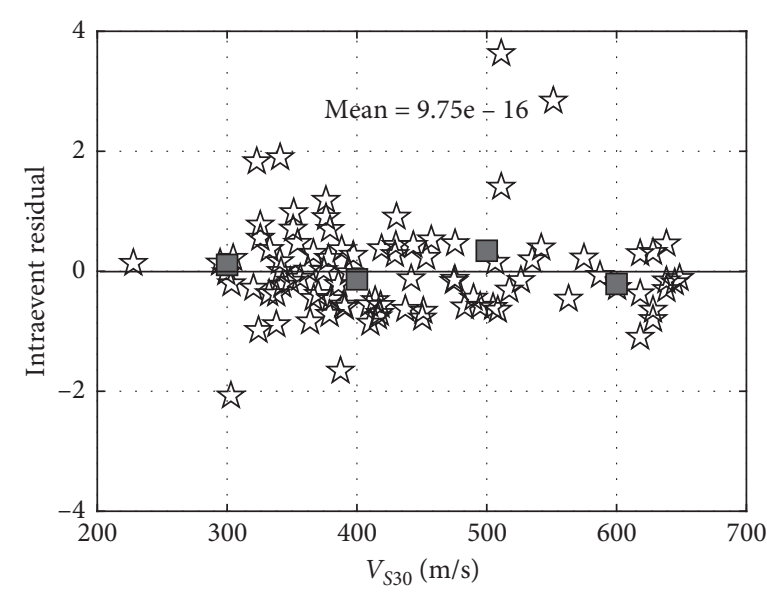

¿ts Residual

Binned mean

(b)

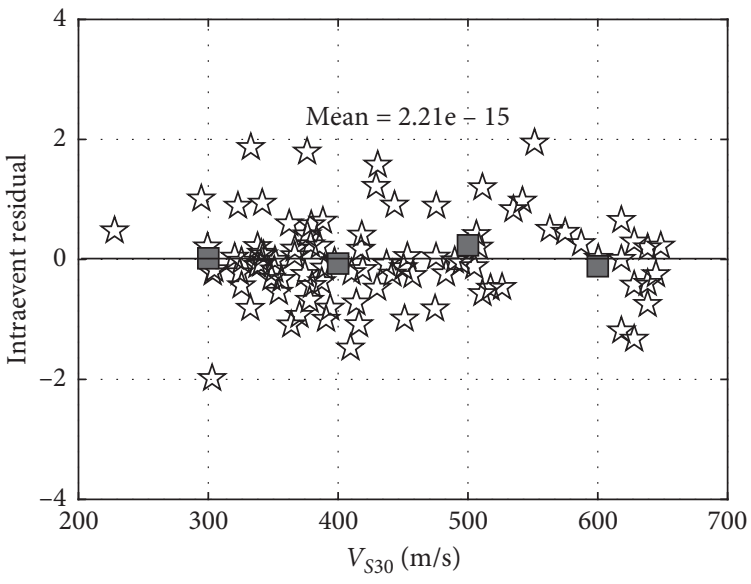

幽 Residual

Binned mean

(c)

(d)

FIgURE 5: Residuals of vertical ground motion and binned mean versus $V_{S 30}$. (a) PGV; (b) PGA; (c) 5\% PSA for $0.1 \mathrm{~s}$; (d) $5 \%$ PSA for $1.0 \mathrm{~s}$.

$\varphi_{\ln Y \mathrm{~V}}$ and $\varphi_{\ln Y \mathrm{~h}}$ are the interevent standard deviation of vertical ground motion and horizontal ground motion, respectively; $\tau_{\ln Y \mathrm{v}}$ and $\tau_{\ln Y \mathrm{~h}}$ are the intraevent standard deviation of vertical ground motion and horizontal ground motion, respectively; and $\rho^{\mathrm{W}} \ln Y_{\mathrm{v}}, \ln Y_{\mathrm{h}}$ and $\rho^{\mathrm{B}}$ $\ln Y_{\mathrm{v}}, \ln Y_{\mathrm{h}}$ are the interevent and intraevent correlation coefficients of residuals between vertical and horizontal ground motion, respectively. The standard deviation of $\ln V / \mathrm{H}$ is listed in Table 1.

Figure 9 shows the $\mathrm{V} / \mathrm{H}$ response spectrum in different distances when $V_{S 30}=300 \mathrm{~m} / \mathrm{s}$ based on regression and the recommended design $\mathrm{V} / \mathrm{H}$ response spectrum for soil site of JTG B02-2013 [28]. The V/H response spectrum based on regression seems to show a bimodal structure with a boundary of about $0.3 \mathrm{~s}$. The intensity of the short-period band decreases obviously with the increase in distances; there are no obvious measurement changes of the longperiod band with the changes of distance except for periods about $10 \mathrm{~s}$ in near field $(1 \mathrm{~km}$ and $10 \mathrm{~km})$. And the design $\mathrm{V} / \mathrm{H}$ response spectrum would misestimate the vertical ground motion in far field.

4.5. Regression Accuracy Comparison. Figure 10 shows the residual comparison of three models based on the vertical ground motion of the Wenchuan earthquake. The residual of the finite fault source model has the smallest scattering of the three models. And the dispersion of the residuals of the multisource model is slightly smaller than that of the point-source model. Standard deviation is an important parameter to measure whether the regression result is reasonable. Concerning the Wenchuan earthquake, standard deviations of vertical ground motion in the multisource model are compared with those in the pointsource model and the finite fault source model computed from equation (4), respectively (see Figure 11). It could be 

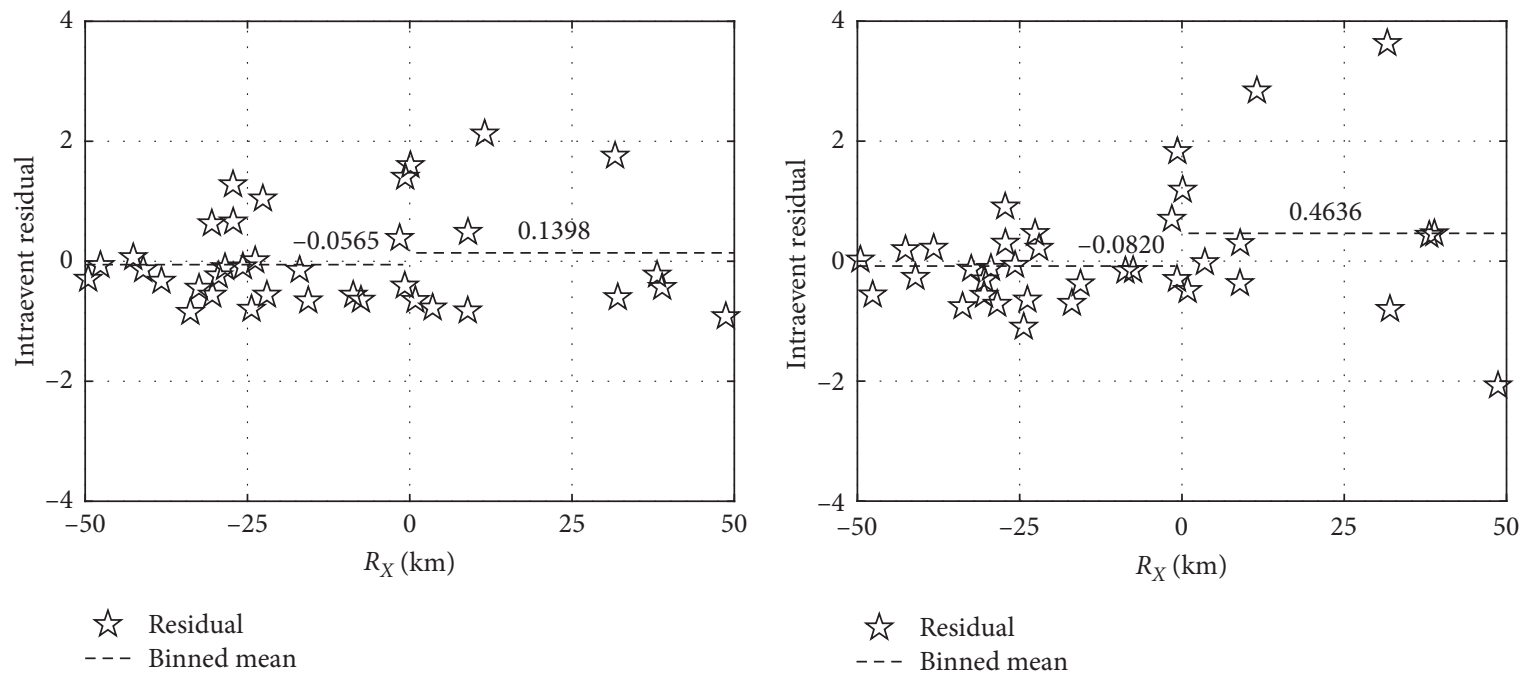

(a)

(b)
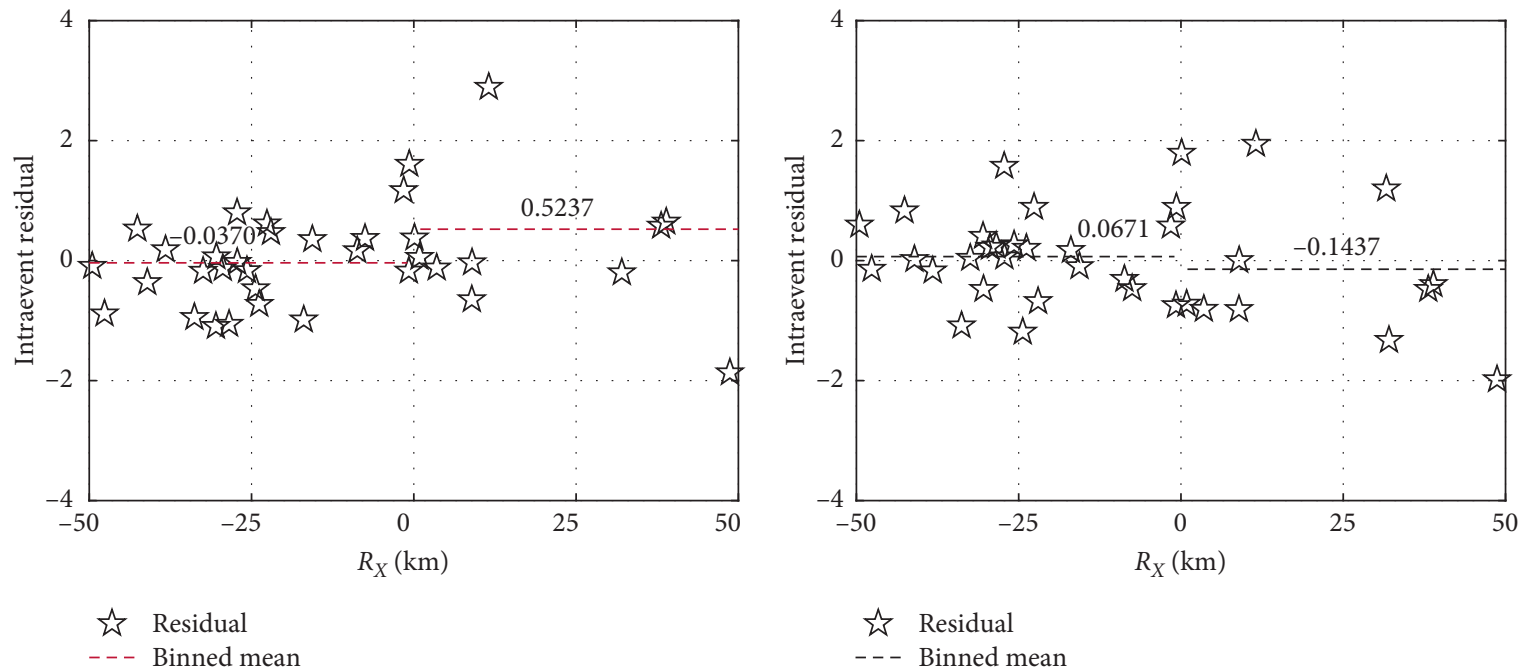

(c)

(d)

FIGURE 6: Residuals of vertical ground motion within $50 \mathrm{~km}$ and binned mean versus $R_{X}$. (a) PGV; (b) PGA; (c) $5 \%$ PSA for $0.1 \mathrm{~s}$; (d) $5 \%$ PSA for $1.0 \mathrm{~s}$.

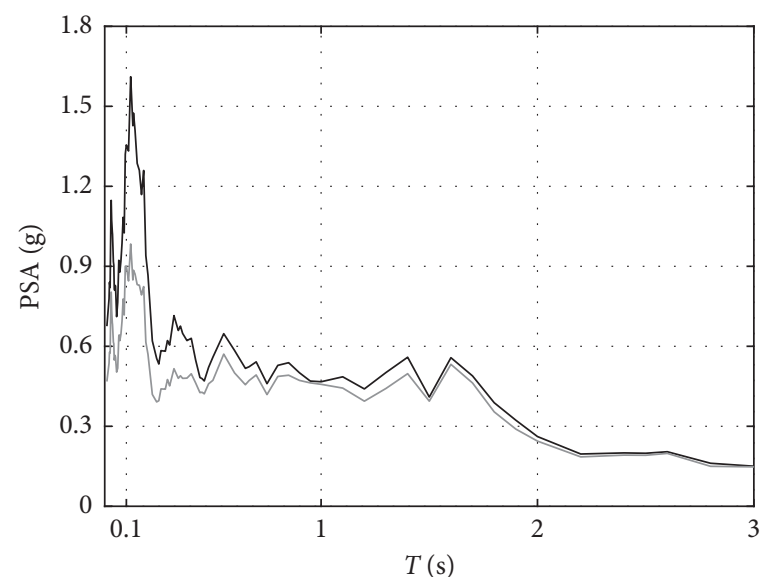

$-V_{S 30}=300 \mathrm{~m} / \mathrm{s}$
$-V_{S 30}=500 \mathrm{~m} / \mathrm{s}$

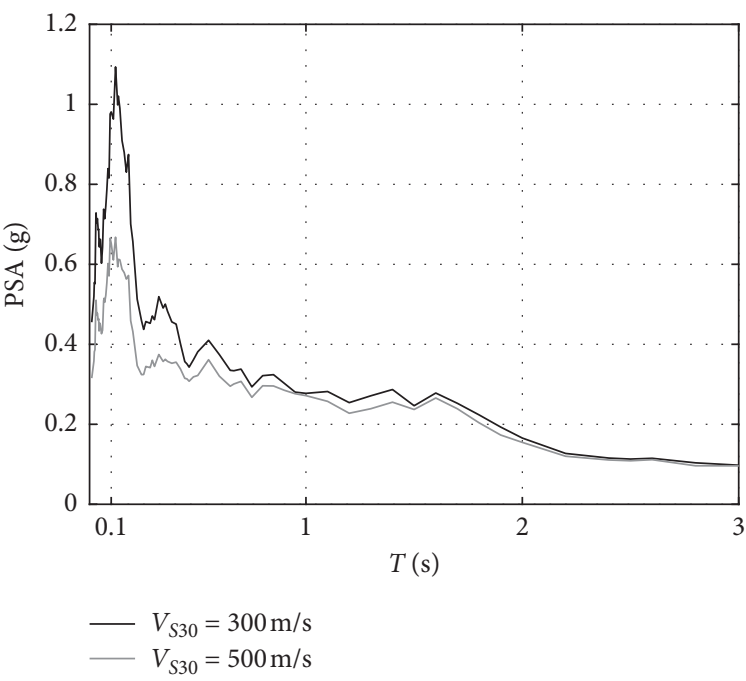

(b)

FIgUre 7: Continued. 


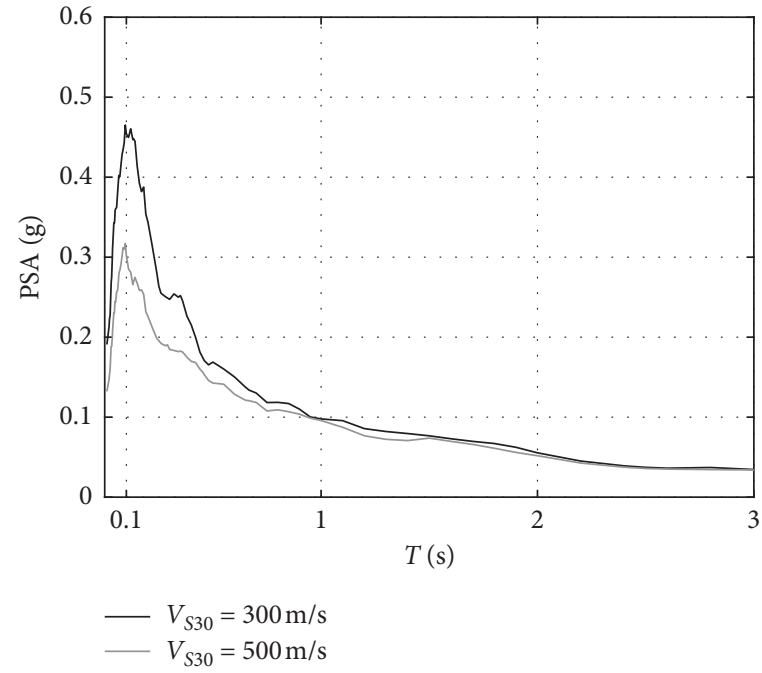

(c)

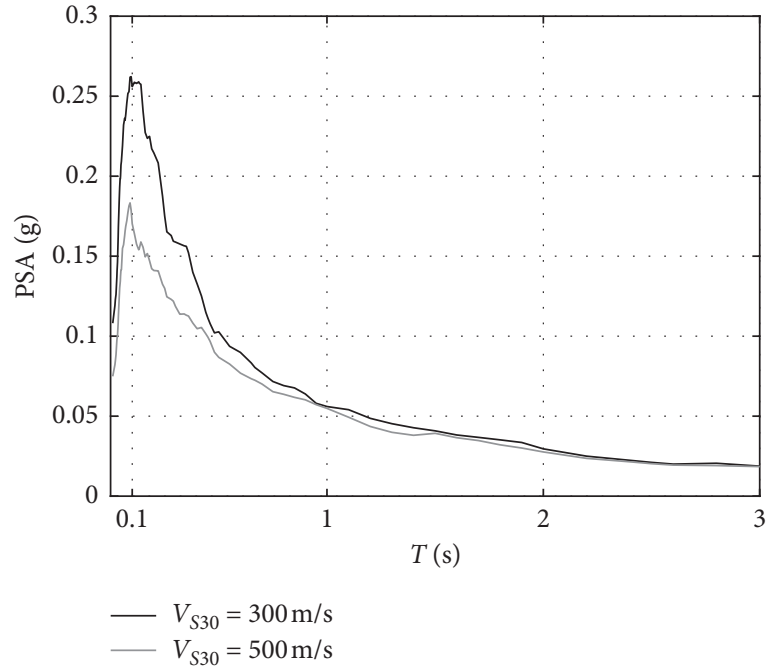

(d)

Figure 7: PSA in different distances based on regression. (a) $1 \mathrm{~km}$; (b) $10 \mathrm{~km}$; (c) $50 \mathrm{~km}$; (d) $100 \mathrm{~km}$.

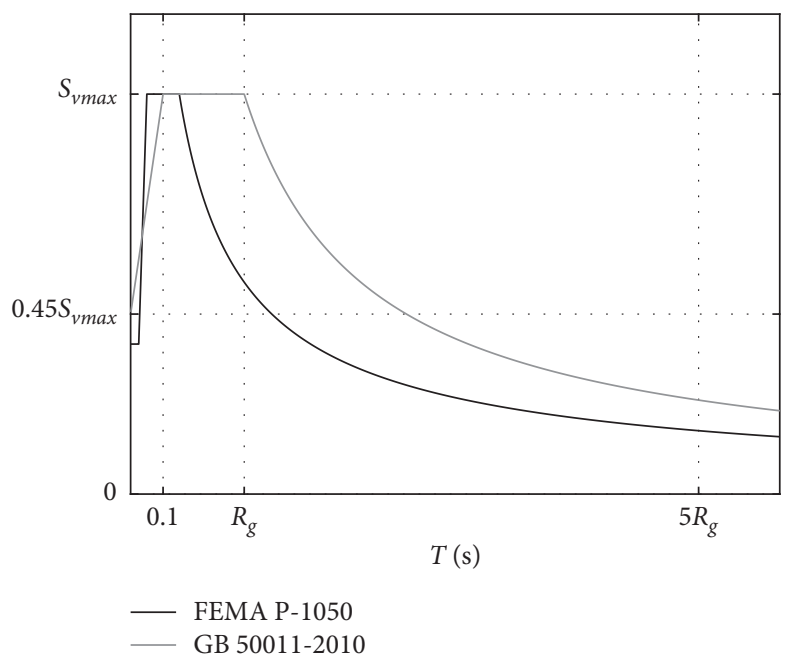

Figure 8: The design vertical response spectrum.

seen that standard deviations in the multisource model are smaller than those in the point-source model and larger than those in the finite fault source model over the entire periods.
The above comparisons indicate that the regression accuracy of the vertical ground motion of the multisource model is slightly higher than that of the point-source model and lower than that of the finite fault source model. 


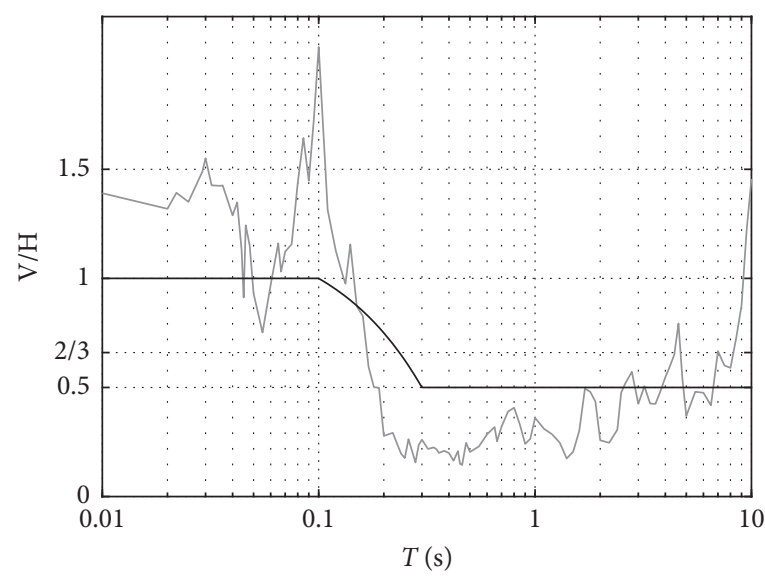

$\mathrm{V} / \mathrm{H}$ spectrum Design $\mathrm{V} / \mathrm{H}$ spectrum

(a)

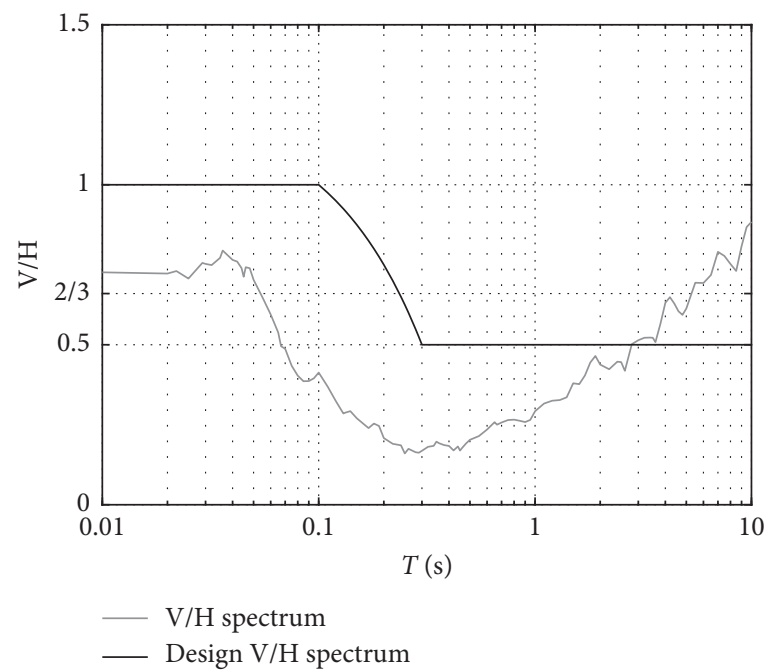

(c)

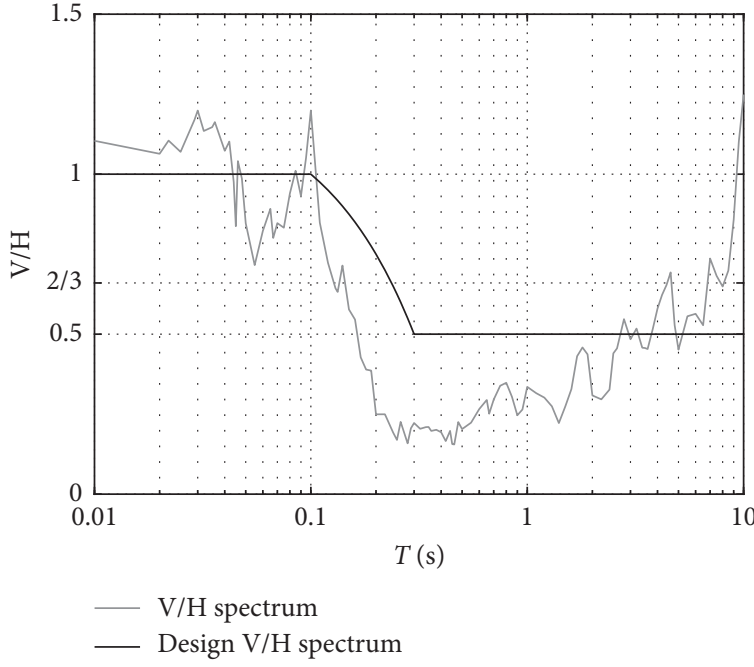

(b)

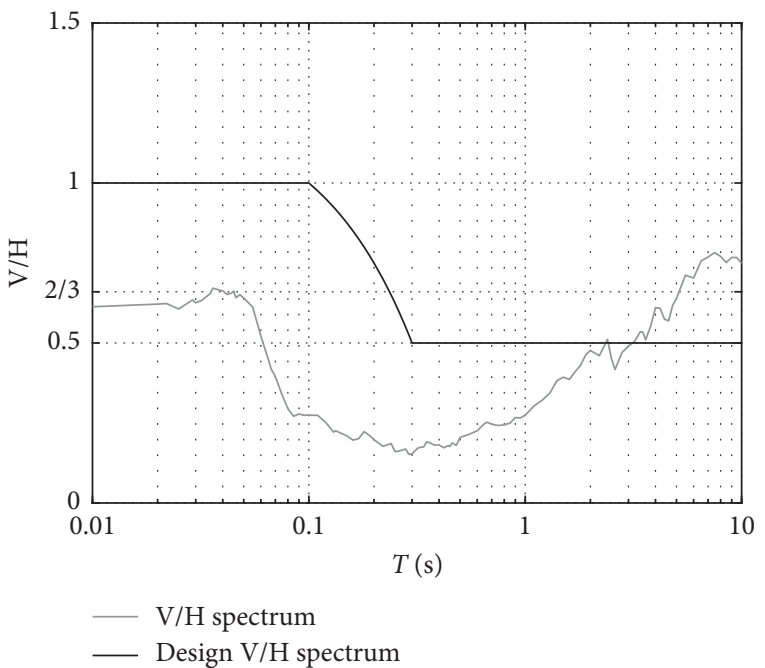

(d)

Figure 9: V/H response spectrum in different distances when $V_{S 30}=300 \mathrm{~m} / \mathrm{s}$ based on regression and the recommended design $\mathrm{V} / \mathrm{H}$ response spectrum for soil site of JTG B02-2013. (a) $1 \mathrm{~km}$; (b) $10 \mathrm{~km}$; (c) $50 \mathrm{~km}$; (d) $100 \mathrm{~km}$.
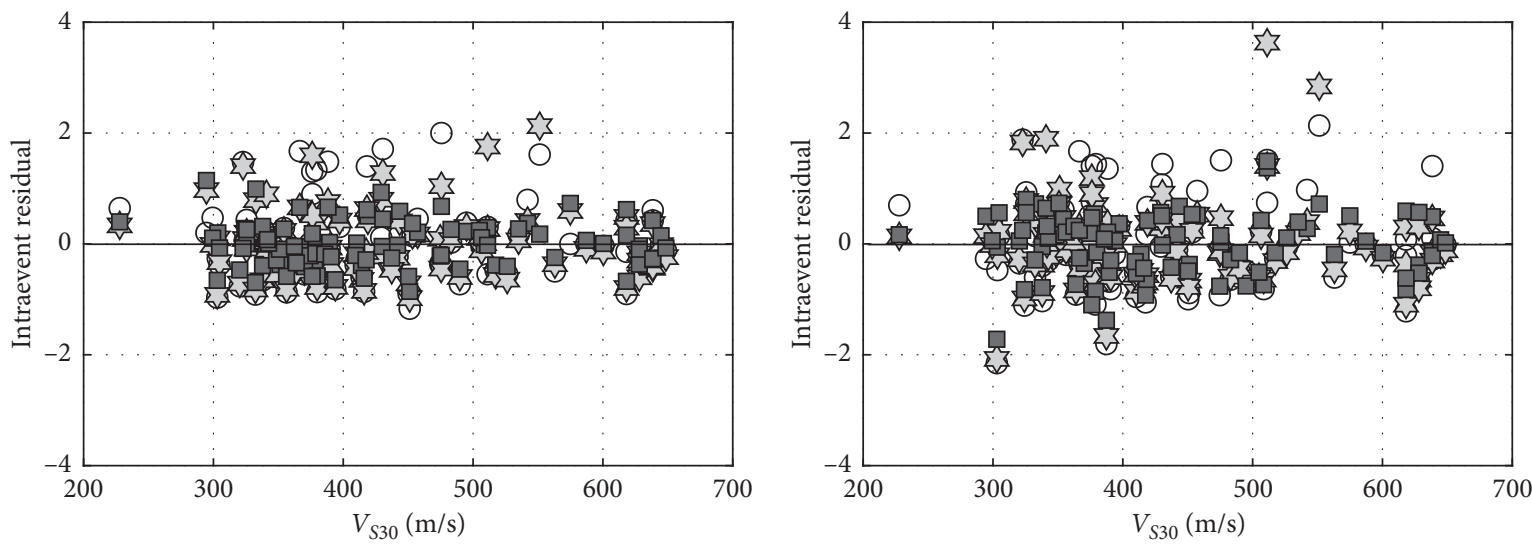

$\bigcirc$ Point-source model

$\Sigma$ Our model

— Finite fault source model

Point-source model

$\Sigma$ Our model

․ Finite fault source model

Figure 10: Continued. 


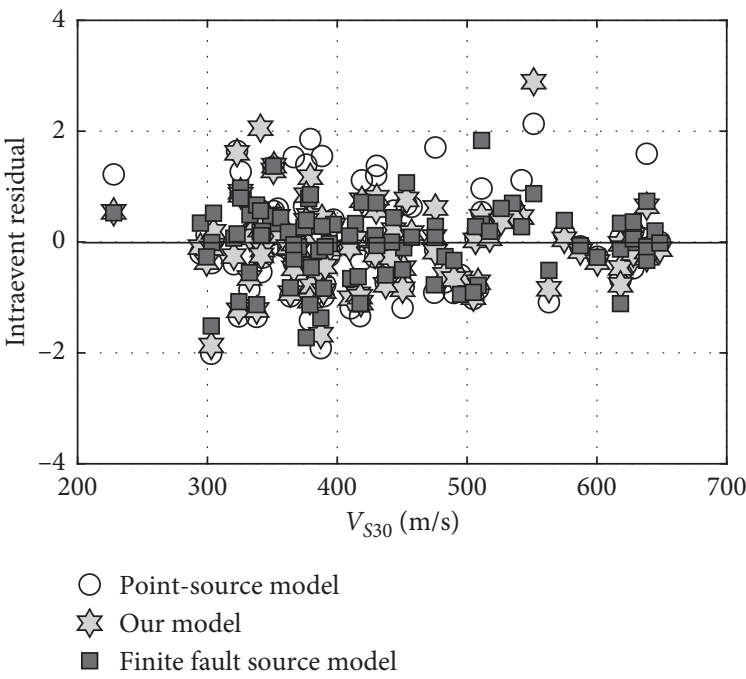

(c)

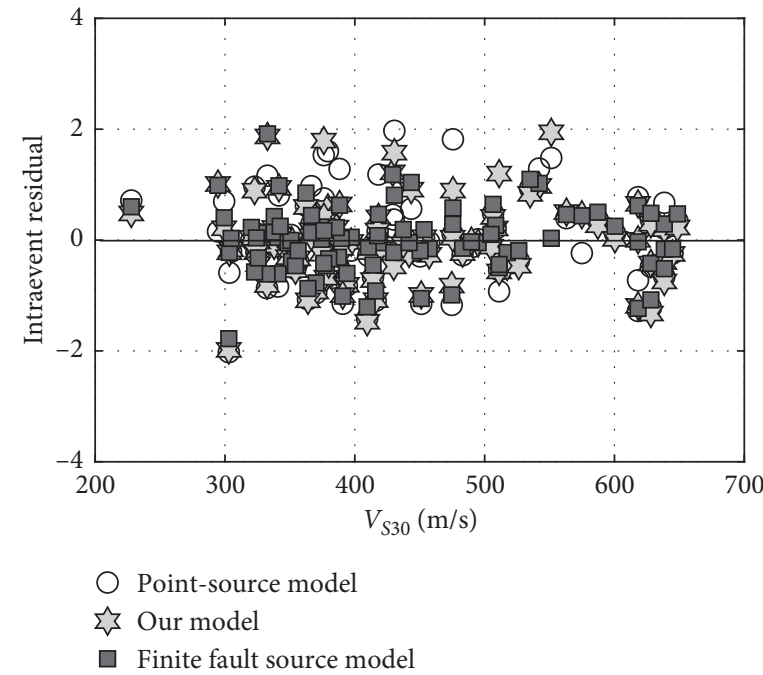

(d)

FIGURE 10: Residuals of vertical ground motion of three models versus $V_{S 30}$. (a) PGV; (b) PGA; (c) 5\% PSA for $0.1 \mathrm{~s}$; (d) 5\% PSA for $1.0 \mathrm{~s}$.

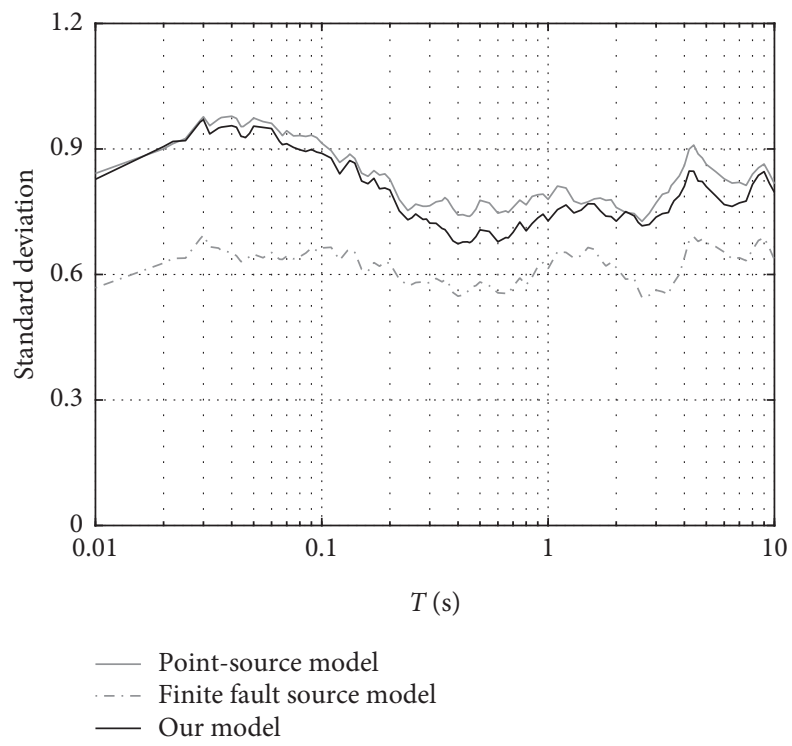

Figure 11: Standard deviations of the multisource model, the point-source model, and the finite fault source model for vertical ground motion of the Wenchuan earthquake.

\section{Discussions and Conclusions}

In this article, we have fitted the vertical ground motion attenuation relationship of the Wenchuan earthquake using the multisource model. According to the regression results, the conclusions have been made as follows:

(1) It has site effect on the vertical ground motion of the Wenchuan earthquake and gradually weakens with the increase in periods. Equation (5) gives rough estimate for site effect on vertical ground motion of the Wenchuan earthquake.

(2) There exists strong hanging-wall effect on vertical ground motion of the Wenchuan earthquake, especially in short periods.

(3) As the shape of horizontal component, the vertical acceleration response spectrum increases to a peak point and then decreases with the increase in periods. The predominant period of vertical acceleration 
response spectrum is about $0.10 \mathrm{~s}$ and is shorter than that of horizontal component. The shape of the vertical response spectrum curves complies with the recommended design vertical response spectrum of FEMA P-1050.

(4) $\mathrm{V} / \mathrm{H}$ shows different characteristics in different distances and periods. In seismic design, the vertical ground motion cannot be estimated simply as $2 / 3$ of the horizontal ground motion, but site location, site condition, and frequency spectrum have to be considered comprehensively. JTG B02-2013 has made great progress, but there are still large deviations in the estimation of the far-field and longperiod vertical ground motion.

(5) The regression accuracy of the vertical ground motion of the multisource model is slightly higher than that of the point-source model and lower than that of the finite fault source model.

These conclusions are consistent with the characteristics of the vertical ground motion of the Wenchuan earthquake based on the finite fault source model [12]. Although there is a gap in regression accuracy between our model and the finite fault source model, it is easier to apply in ground motion prediction engineering because of the simplification of distance definition. It is expected that this model will serve as an alternative for source-to-site distance when multiple asperities are to be modeled in the absence of the detail fault model to get a general scenario of the future ground motions. The regression coefficients presented in this paper may only provide reference values for earthquakes like the 2008 Wenchuan earthquake and may not be suitable for other events. So, the results should be used carefully.

\section{Data Availability}

The data used to support the findings of this study are available from the corresponding author upon request.

\section{Conflicts of Interest}

The authors declare that they have no conflicts of interest.

\section{Acknowledgments}

This research has been supported by the National Natural Science Foundation of China (Project no. 51808444).

\section{References}

[1] X. J. Li, Z. H. Zhou, H. Y. Yu et al., "Strong motion observations and recordings from the great Wenchuan earthquake," Earthquake Engineering and Engineering Vibration, vol. 7, no. 3, pp. 235-246, 2008.

[2] H. Nh and A. Kumar, "Ground motion prediction equation for North India, applicable for different site classes," Soil Dynamics and Earthquake Engineering, vol. 139, Article ID 106425, 2020.

[3] X. L. Zhang, Y. S. Zhang, and H. Wu, "The relationship between the point-source distance and the fault-source distance in ground motion prediction equation," Earthquake Engineering and Engineering Vibration, vol. 38, no. 1, pp. 178-189, 2018, in Chinese.

[4] A. D. Kiureghian and A. H.-S. Ang, "A fault-rupture model for seismic risk analysis," Bulletin of the Seismological Society of America, vol. 67, no. 4, pp. 1173-1194, 1977.

[5] P. Liu and Q. F. Luo, "Wenchuan earthquake peak acceleration attenuation relationship of multiple circle model," Journal of Central South University (Science and Technology), vol. 46, no. 6, pp. 2317-2323, 2015, in Chinese.

[6] P. Liu and Q. F. Luo, "Multi-circle ground motions attenuation model of NGA database," Journal of Harbin Institute of Technology, vol. 49, no. 6, pp. 164-170, 2017, in Chinese.

[7] Q. F. Luo and Y.X. Hu, "Semi-empirical method of simulating near-fault and far-field acceleration of the 1976 Tangshan earthquake," Acta Seismologica Sinica, vol. 19, no. 9, pp. 275-282, 1997, in Chinese.

[8] N. A. Abrahamson and W. J. Silva, "Summary of the Abrahamson \& Silva NGA ground-motion relations," Earthquake Spectra, vol. 24, no. 1, pp. 67-97, 2008.

[9] R. K. Mark and M. G. Bonilla, "Regression analysis of earthquake magnitude and surface fault length using the 1970 data of Bonilla and Buchanan," USGS Open-File Report 77-614, 1977.

[10] J. P. Stewart, D. M. Boore, E. Seyhan, and G. M. Atkinson, "NGA-west2 equations for predicting vertical-component PGA, PGV, and 5\%-damped PSA from shallow crustal earthquakes," Earthquake Spectra, vol. 32, no. 2, pp. 1005-1031, 2016.

[11] Y. Bozorgnia and K. W. Campell, "Vertical ground motion model for PGA, PGV, and linear response spectra using the NGA-West2 database," Earthquake Spectra, vol. 32, no. 2, pp. 979-1004, 2016.

[12] P. Liu, Q. F. Luo, and X. Z. Chen, "Vertical ground motion attenuation relationship of Wenchuan earthquake," Journal of Harbin Institute of Technology, vol. 52, no. 2, pp. 119-128, 2020, in Chinese.

[13] Z. Gülerce, R. Kamai, N. A. Abrahamson, and W. J. Silva, "Ground motion prediction equations for the vertical ground motion component based on the NGA-W2 database," Earthquake Spectra, vol. 33, no. 2, pp. 499-528, 2017.

[14] M. A. Jaimes and A. D. García-Soto, "Updated ground motion prediction model for Mexican intermediate-depth intraslab earthquakes including V/H ratios," Earthquake Spectra, vol. 36, no. 3, pp. 1298-1330, 2020.

[15] H. Javan-Emrooz, M. Eskandari-Ghadi, and N. Mirzaei, "Prediction equations for horizontal and vertical PGA, PGV, and PGD in northern Iran using prefix gene expression programming," Bulletin of the Seismological Society of America, vol. 108, no. 4, pp. 2305-2332, 2018.

[16] T. D. Ancheta, R. B. Darragh, J. P. Stewart et al., "NGA-West2 database," Earthquake Spectra, vol. 30, no. 2, pp. 989-1005, 2014.

[17] Y. Choi and J. Stewart, "Nonlinear site amplification as function of $30 \mathrm{~m}$ shear wave velocity," Earthquake Spectra, vol. 21, no. 1, pp. 1-30, 2005.

[18] Federal Emergency Management Agency (FEMA), NEHRP Recommended Seismic Provisions for New Buildings and Other Structures, FEMA, Washington, D. C., USA, 2015.

[19] Ministry of Housing and Urban-Rural Development of the People's Republic of China (MOHURD), Code for Seismic of Buildings, GB 50011-2010, MOHURD, Beijing, China, 2016, in Chinese. 
[20] N. M. Newmark and W. J. Hall, Earthquake Spectra and Design, Earthquake Engineering Research Institute, Berkeley, CA, USA, 1982.

[21] N. A. Abrahamson and J. J. Litehiser, "Attenuation of vertical peak acceleration," Bulletin of the Seismological Society of America, vol. 79, no. 3, pp. 549-580, 1989.

[22] M. Niazi and Y. Bozorgnia, "Behavior of near-source vertical and horizontal response at SMART-1 array, Taiwan," Earthquake Engineering \& Structural Dynamics, vol. 21, no. 1, pp. 37-50, 1992.

[23] N. N. Ambraseys and K. A. Simpson, "The prediction of vertical response spectra in Europe," Earthquake Engineering \& Structural Dynamics, vol. 25, no. 4, pp. 401-412, 1996.

[24] Z. H. Zhou, Y. N. Zhou, T. Lu, and C. Yang, "Study on characteristics of vertical ground motion," Earthquake Engineering and Engineering Vibration, vol. 23, no. 3, pp. 25-29, 2003, in Chinese.

[25] Z. Gülerce and N. A. Abrahamson, "Site-specific design spectra for vertical ground motion," Earthquake Spectra, vol. 27, no. 4, pp. 1023-1047, 2011.

[26] S. Akkar, M. A. Sandikaya, and B. Ö. Ay, "Compatible ground-motion prediction equations for damping scaling factors and vertical-to-horizontal spectral amplitude ratios for the broader European region," Bulletin of Earthquake Engineering, vol. 12, no. 1, pp. 517-547, 2014.

[27] Y. Bozorgnia and K. W. Campell, "Ground motion model for the vertical-to-horizontal $(\mathrm{V} / \mathrm{H})$ ratios of $\mathrm{PGA}, \mathrm{PGV}$, and response spectra," Earthquake Spectra, vol. 32, no. 2, pp. 951-978, 2016.

[28] Ministry of Transport of the People's Republic of China (MTPRC), Specification of Seismic Design for Highway Engineering: JTG B02-2013, MTPRC, Beijing, China, 2013, in Chinese. 